\title{
NURSE CALL OTOMATIS DENGAN SENSOR BEAT PER MINUTES (BPM) BERBASIS INTERNET OF THINGS (IOT)
}

\author{
Purwiyanto $^{1)}$, Cahya Vikasari ${ }^{2)}$, Dwi Novia Prasetyanti ${ }^{3)}$ dan Galih Mustiko Aji ${ }^{4)}$ \\ ${ }^{1,4}$ Teknik Elektronika, Politeknik Negeri Cilacap, Jl. Dr. Soetomo No.1, Cilacap, 53212 \\ ${ }^{2,3}$ Teknik Informatika, Politeknik Negeri Cilacap, Jl. Dr. Soetomo No.1, Cilacap, 53212 \\ E-mail: purwi_1979@yahoo.com
}

\begin{abstract}
Nurse call is a device which used by inpatient care facility to call nurse or other medical staff. Within some condition, the patient can't make a call. Therefore, it is necessary to make a device that function for monitoring patient's heartbeat as an indicator to give medical service. The sensor of Beat per Minutes is installed on the patien's body that connected to network of Internet of Things (IoT) in order to be capable of communicating with the available information System in Nurse station. The sensor implementation on the network of IoT shows that the sensor data from 60 to $100 \mathrm{bpm}$ is a normal condition. The more or less sensor data from the normal condition will give a warning on the Information System in Nurse Station.
\end{abstract}

Keywords: Nurse call, Internet of Things, heart rate Sensor, Embedded System, Microcontroller.

\begin{abstract}
ABSTRAK
Nurse call merupakan perangkat yang digunakan pasien rawat inap untuk memanggil perawat atau petugas medis lainnya. Dalam beberapa kondisi pasien tidak dapat melakukan panggilan, oleh karena itu diperlukan suatu perangkat yang berfungsi untuk memantau detak jantung pasien sebagai indikator untuk memberikan pelayanan medis. Sensor Beat per Minutes (BPM) dipasang pada tubuh pasien yang terhubung pada jaringan Internet of Things (IoT) agar dapat berkomunikasi dengan Sistem Informasi yang ada di Nurse Station. Implementasi sensor pada jaringan IoT menunjukkan data sensor 60 sampai dengan 100 bpm merupakan kondisi normal. Data sensor lebih atau kurang dari kondisi normal akan memberikan peringatan pada Sistem Informasi yang terdapat di Nurse Station.
\end{abstract}

Kata Kunci: Nurse call, Internet of Things, Sensor detak jantung, Sistem embedded, Mikrokontroler.

\section{PENDAHULUAN}

Nurse call merupakan alat pemanggil petugas medik yang diinstal pada ruang rawat inap pasien di rumah sakit atau fasilitas kesehatan lainnya. Nurse call dilengkapi dengan tombol yang apabila ditekan akan mengirimkan pesan ke ruang petugas medik, yang menandakan pasien membutuhkan pelayanan medik. Dengan adanya nurse call, pasien atau anggota keluarga pasien tidak perlu lagi keluar ruang perawatan.

Indikator keberhasilan penanggulangan medik bergantung pada kecepatan petugas medik untuk memberikan pertolongan (Surtiningsih, 2016). Keberhasilan waktu tanggap atau response time sangat tergantung kepada kecepatan yang tersedia serta kualitas pemberian pertolongan untuk menyelamatkan nyawa atau mencegah cacat. Peran nurse call sangat membantu petugas medik untuk meningkatkan kecepatan petugas dalam memberikan pertolongan.

Dalam beberapa kondisi membuat pasien tidak bisa menekan tombol pada nurse call untuk memanggil petugas medik, seperti pada pasien yang memiliki kelainan jantung. Jantung merupakan organ vital dan merupakan pertahanan terakhir untuk hidup selain otak. Denyut yang ada di jantung tidak bisa dikendalikan oleh manusia. Denyut jantung biasanya mengacu pada jumlah 
waktu yang dibutuhkan oleh detak jantung per satuan waktu. Secara umum hal tersebut direpresentasikan sebagai beats per minute (BPS). Denyut jantung manusia dewasa rata-rata yaitu : 60 100 bpm. Jika memang denyut jantung di bawah atau di atas standar, maka terdapat kemungkinan organ jantung mengalami masalah (Bararah, 2010). Sensor BPS diimplementasikan pada nurse call untuk memonitoring kondisi pasien yang memiliki kelainan pada organ jantung secara kontinyu. Implementasi sensor BPS pada nurse call akan memberikan informasi tentang kondisi pasien secara langsung di ruang petugas medik sehingga dapat digunakan untuk meningkatkan waktu tanggap petugas dalam memberikan pelayanan kesehatan ke pasien.

Nurse call diinstal untuk masing-masing pasien disetiap ruang rawat inap, yang artinya dibutuhkan node-node sensor yang harus terintegrasi ke ruang petugas medik. Implementasi Internet of Things (IoT) memungkinkan pemasangan nodenode sensor pada tubuh pasien maupun ruang inap. IoT merupakan evolusi dari internet yang memiliki kemampuan untuk mengumpulkan, menganalisa, dan mendistribusikan data (Evans, 2011). IoT mampu menghubungkan lebih banyak perangkat untuk dapat berkomunikasi dengan manusia. Perangkat IoT diberikan identitas agar dapat beroperasi secara intelijen, dan bisa berkomunikasi dengan sosial, lingkungan dan pengguna. IoT banyak diaplikasikan untuk sistem monitoring dengan memanfaatkan node-node sensor seperti identifikasi radio frekuensi (RFID), sensor infra merah, GPS, scanner, dan smart meter (Momoh, 2009). Sensor yang ada dalam jaringan IoT berfungsi untuk mendeteksi parameter-parameter sebuah peralatn melalui jaringan komunikasi kabel maupun nirkabel sehingga mampu untuk memperoleh data yang akurat serta proses kendali secara real-time (Hidayatullah, 2017).

Dalam artikel ini akan dibahas monitoring detak jantung (BPM) pada sistem nurse call berbasis Internet of Things yang dapat memberikan informasi dan indikator kepada petugas medik agar dapat meningkatkan pelayanan rumah sakit atau fasilitas kesehatan lain.

\section{METODE PENELITIAN}

Pengontrol utama pada nurse call melibatkan WeMos D1 yaitu papan mikrokontroler arduino yang sudah dilengkapi perangkat WiFi ESP8266 yang memungkinkan nurse call terhubung pada jaringan komputer melalui jaringan nirkabel WiFi. Blok diagram dari sistem nurse call digambarkan sebagai berikut :

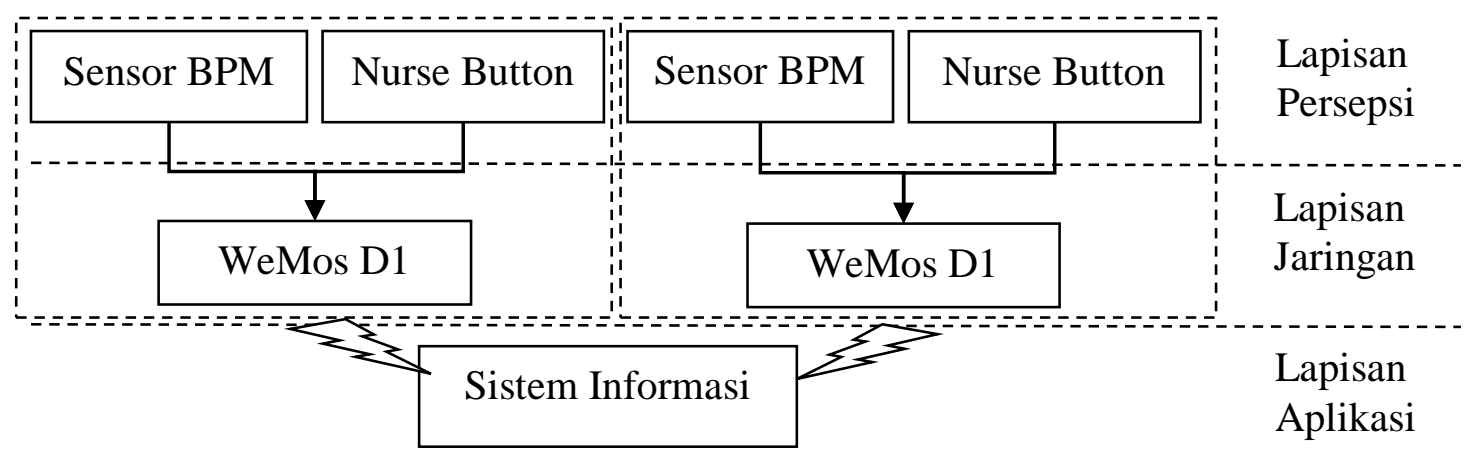

Gambar 1. Struktur IoT pada nurse call 
Lapisan persepsi (sensing) terdiri dari sensor BPM dan nurse button yang menjadi perangkat masukan WeMos D1. Sensor BPM yang digunakan adalah easy pulse plugin seperti yang ditunjukkan pada Gambar 2 berikut ini.

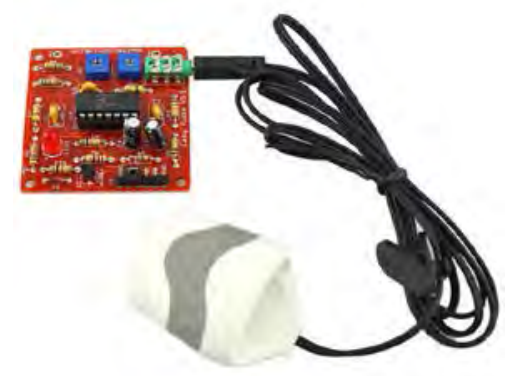

Gambar 2. Sensor easy pulse plugin

Easy pulse plugin adalah sensor detak jantung yang bekerja menggunakan prinsip photoplethysmography (PPG), yaitu metode non-invasive untuk mengukur detak jantung (cardiovascular) dengan cara mendeteksi volume aliran darah di dalam nadi yang berada sangat dekat dengan kulit. Sensor easy pulse plugin menggunakan LED infra merah dan photodetector, dimana denyut nadi dijari akan mempengaruhi aliran cahaya dari LED infra merah ke photodetector. Sedangkan untuk nurse button menggunakan dua buah tombol seperti yang ditunjukkan pada Gambar 3 berikut.

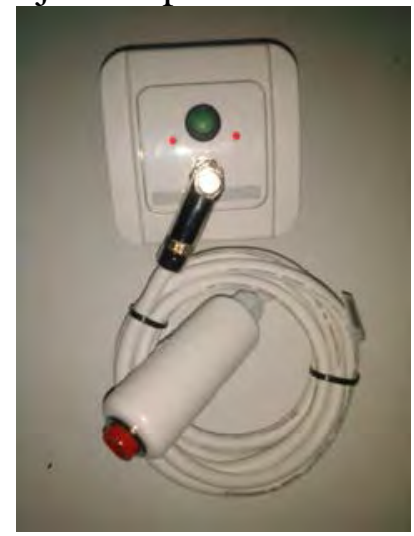

Gambar 3. Nurse button
Nurse button seperti yang ditunjukkan pada Gambar 3 terdiri dari dua tombol, dimana satu tombol berwarna merah digunakan oleh pasien untuk melakukan pemanggilan ke petugas medik dan satu tombol berwarna hijau digunakan oleh petugas medik untuk menghentikan indikator yang ada diruang petugas medik yang artinya petugas medik telah berada atau sudah selesai memberikan pertolongan/pelayanan kepada pasien.

Lapisan jaringan memungkinkan perangkat pada lapisan persepsi untuk terhubung ke jaringan komputer, baik dengan menggunakan kabel maupun nirkabel. Perangkat yang digunakan pada lapisan jaringan adalah WeMos D1 yang sudah terintegrasi modul WiFi 2,4 GHz seperti yang ditunjukkan pada Gambar 4 berikut ini.

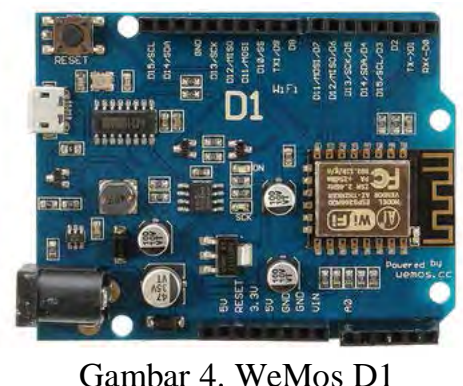

WeMos D1 selain digunakan sebagai kendali utama dari lapisan persepsi juga digunakan pada lapisan jaringan untuk terhubung dengan jaringan WiFi ke antarmuka pengguna (lapisan aplikasi). Aplikasi berbasis webserver digunakan sebagai antarmuka petugas medik dengan perangkat nurse call.

Detail dari sistem nurse call dengan sensor BPM dapat dilihat pada diagram alir Gambar 5 berikut ini. 


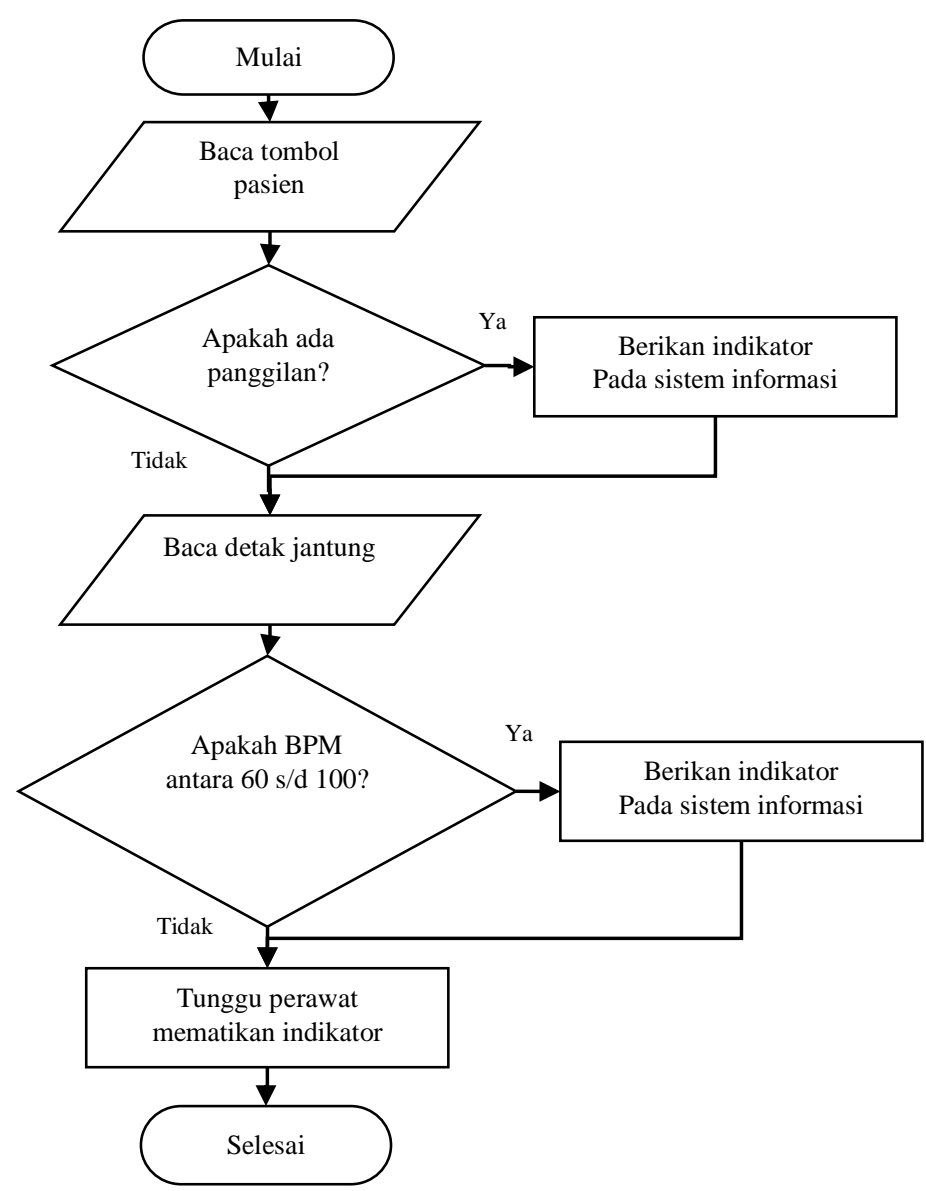

Gambar 5. Diagram alir sistem nurse call

\section{HASIL DAN PEMBAHASAN}

Perangkat keras dirangkai dan difabrikasi menjadi sistem yang berjalan sesuai desain perancangan. Nurse call berbasis IoT hasil perancangan ditunjukkan pada Gambar 6 berikut.

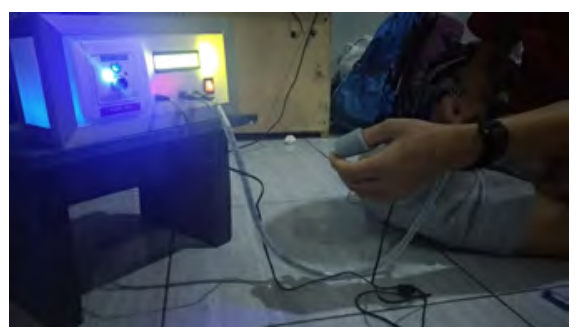

Gambar 6. Sistem nurse call berbasis IoT

Pada nurse call terdapat penampil berupa LCD karakter yang menampilkan data detak jantung dalam satuan bpm, dan status pemanggilan perawat. Untuk mengetahui performa dari nurse call maka dilakukan pengujian sensor BPM dan pengujian sistem secara keseluruhan.
Pengujian sensor BPM dilakukan dengan membandingkan rangkaian sensor dengan perangkat lain. Perangkat yang digunakan sebagai alat uji adalah Omron BPM type : HEM-6121.

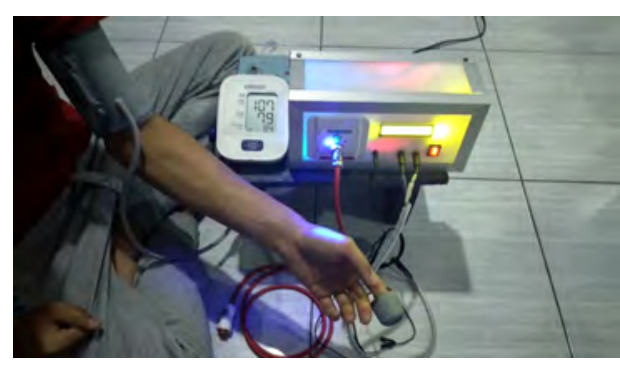

Gambar 7. Pengujian sensor BPM

Pengujian dilakukan dengan memasang kedua perangkat yaitu alat uji pada pergelangan tangan dan rangkaian sensor pada jari telunjuk seperti yang ditunjukkan pada Gambar 7. Hasil pengujian sensor BPM dapat dilihat pada Tabel 1 berikut ini. 
Tabel 1. Hasil pengujian sensor BPM

\begin{tabular}{clccc}
\hline No & Objek yang diukur & $\begin{array}{c}\text { Sensor } \\
\text { (BPM) }\end{array}$ & $\begin{array}{c}\text { Alat Uji } \\
\text { (BPM) }\end{array}$ & Selisih \\
\hline 1 & $\begin{array}{l}\text { Tangan kanan - jari } \\
\text { telunjuk }\end{array}$ & 76 & 82 & 6 \\
\hline 2 & $\begin{array}{l}\text { Tangan kanan - jari } \\
\text { tengah }\end{array}$ & 74 & 80 & 6 \\
\hline 3 & $\begin{array}{l}\text { Tangan kanan - jari } \\
\text { manis }\end{array}$ & 78 & 83 & 5 \\
\hline 4 & $\begin{array}{l}\text { Tangan kanan - jari } \\
\text { kelingking }\end{array}$ & 80 & 84 & 4 \\
\hline 5 & $\begin{array}{l}\text { Tangan kanan - } \\
\text { jempol }\end{array}$ & 0 & 76 & 76 \\
\hline 6 & $\begin{array}{l}\text { Tangan kiri - jari } \\
\text { telunjuk }\end{array}$ & 80 & 78 & 2 \\
\hline 7 & $\begin{array}{l}\text { Tangan kiri - jari } \\
\text { tengah }\end{array}$ & 79 & 82 & 3 \\
\hline 8 & $\begin{array}{l}\text { Tangan kiri - jari } \\
\text { manis }\end{array}$ & 78 & 80 & 2 \\
\hline 9 & $\begin{array}{l}\text { Tangan kiri - jari } \\
\text { kelingking }\end{array}$ & 82 & 80 & 2 \\
\hline 10 & Tangan kiri - jempol & 0 & 82 & 82 \\
\hline
\end{tabular}

Hasil pengujian seperti pada Tabel 1 menunjukkan bahwa pemasangan sensor BPM tidak dapat dilakukan pada jari jempol, sedangkan untuk jari yang lain simpangan terbesarnya adalah $7 \%$. Nilai simpangan tersebut masih dianggap baik untuk diimplementasikan pada sistem nurse call yang dibuat.

Pengujian selanjutnya adalah pengujian sistem nurse call secara keseluruhan yang dimaksudkan untuk mengetahui proses pembacaan detak jantung, transmisinya pada jaringan dan aksi pada aplikasi. Pengujian pertama dilakukan dengan menekan tombol merah yang berarti pasien melakukan pemanggilan kepada petugas medik. Antarmuka pada aplikasi akan memberikan indikator bahwa pasien melakukan pemanggilan seperti yang ditunjukkan pada Gambar 8 berikut.

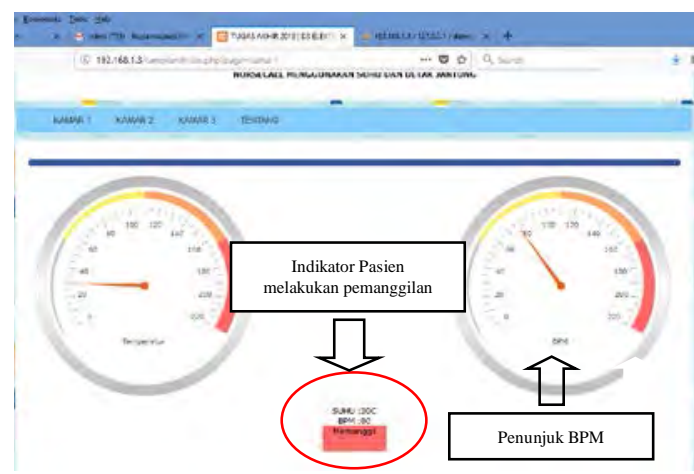

Gambar 8. Antarmuka petugas medik

Dari Gambar 8 di atas dapat diketahui bahwa antarmuka memberikan respon ketika tombol merah pada nurse call ditekan. Indikator tersebut tetap menyala sampai tombol hijau pada nurse call ditekan. Pada antarmuka juga disediakan penunjuk BPM yang menunjukkan detak jantung pasien secara real-time. Dari pengujian yang telah dilakukan, menunjukkan bahwa indikator akan diberikan ketika detak jantung pasien di bawah nilai 60 dan di atas 100 .

\section{KESIMPULAN}

Dari pengujian yang telah dilakukan maka kesimpulan dari hasil perancangan sistem nuse call otomatis dengan sensor BPM adalah sebagai berikut :

1) Penggunaan sensor easy pulse plugin memiliki simpangan sebesar $7 \%$ namun masih sangat baik untuk diimplementasikan pada sistem nurse call.

2) Implementasi nurse call pada jaringan IoT memungkinkan pemantauan pasien secara real-time, sehingga memudahkan petugas medik untuk memberikan pertolongan/pelayanan secepat mungkin.

\section{DAFTAR PUSTAKA}

[1] Bararah, Vera Farah. 2010, 29 Maret. Berapa Jumlah Denyut Jantung Normal?.

http://health.detik.com/read/2010/03/2 9/135029/1327738/766/berapajumlahdenyut-jantung-normal

[2] Evans, Dave. (2011). The Internet of Things "How the Next Evolution of the Internet Is Changing Everything”. Cisco Internet Business Solutions Group (IBSG).

[3] Hidayatullah, Nur Asyik. 2017. Desain dan Aplikasi Internet of Thing (IOT) untuk Smart Grid Power System. Jurnal VOLT, Vol. 2 No.1 April 2017:35-44. 
Purwiyanto, dkk. Nurse Call Otomatis...

[4] Momoh, JA. (2009). Smart Grid Design for Efficient and Flexible Power Networks Operation and Control. Power Systems Conference and Exposition. IEEE/PES:1-8.

[5] Surtiningsih, Dwi. Susilo, Cipto. Hamid, Mohammad Ali. (2016). Penerapan Response Time Perawat dalam Pelaksanaan Penentuan Prioritas Penanganan

Kegawatdaruratan pada Pasien Kecelakaan di IGD RSD Balung. The Indonesian Journal of Health Science, 6(2), 124-132. 